\title{
University knowledge spillover from an Open Innovation Technology Transfer context
}

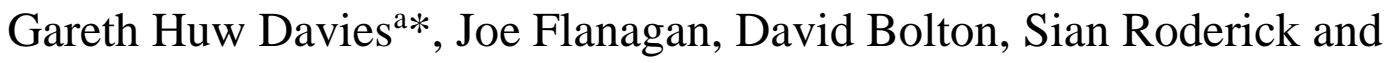
Naomi Joyce ${ }^{b}$

${ }^{a}$ School of Management, Swansea University, Swansea, UK; ${ }^{b}$ School of Medicine, Swansea University, Swansea, UK

g.h.davies@swansea.ac.uk, School of Management, Swansea University, Fabian Way, Swansea, SA1 8EP

\section{University knowledge spillover from an Open Innovation Technology Transfer context}

University research output is recognised as a source of new knowledge in spillover theory and has been targeted by governments and other stakeholders to support knowledge-based regional economic development. This paper reflects upon the 'AgorIP' Technology Transfer initiative to examine how a university can support knowledge spillover within an innovation ecosystem. This aims to help provide greater understanding of how local characteristics moderate knowledge spillover supported new enterprise, as called for by Ghio, Guerini, Lehmann, and Rossi-Lamastra (2015). AgorIP supports academics in entrepreneurship and extends the traditional technology transfer context to one which also involves health system research output. Responding to the call by Jones, Klapper, Ratten, and Fayolle (2018) this paper extends contextual spillover research through university and regional policy, by examining AgorIP activities, including its portfolio of completed projects and current partners. The findings present spatial concentration within the Swansea Bay City Region (SBCR), along with focus on targeted smart specialisations, not least Life Sciences \& Health. The peripheral post-industrial region nature of SBCR makes AgorIP's context 
of potential interest to other regions looking to harness the potential of university and other public research organisations in developing knowledge-based enterprise.

Keywords: knowledge spillover; technology transfer; smart specialisation; regional policy 


\section{Introduction}

Knowledge spillover from universities has long-been considered as positively

influencing regional economic development (David B. Audretsch \& Lehmann, 2005). In this context, university research output, considered as a public good adds to the stock of knowledge available for entrepreneurial opportunities. Etzkowitz, Webster, Gebhardt, and Terra (2000) described universities as shifting from 'ivory tower to entrepreneurial paradigm', at the same time as seminal work (Etzkowitz \& Leydesdorff, 2000; Leydesdorff \& Etzkowitz, 1998) began discussion of a 'triple helix' paradigm of engagement between academia, industry and government. The triple helix model stresses the role of government policy to support knowledge transfer, which is of specific importance within peripheral regions (Faria, Mixon, \& Upadhyaya, 2019; Teixeira, Veiga, \& Fernandes, 2019). Consideration of university contribution to economic development has often emphasised contribution to universities' localities (Charles, 2003), including how different university types relate to their local contexts (Guerrero, Cunningham, \& Urbano, 2015; Hewitt-Dundas, 2012). University activities involve formal and informal interactions (Ratten, 2017), which include the role of technology transfer, which is considered within the concept of Entrepreneurial Universities (Gibb \& Hannon, 2006). The global impact of Entrepreneurial Universities has been demonstrated within works such as those presented by J. Ferreira, Fayolle, Ratten, and Raposo (2018). In this context, the role of Entrepreneurial Universities in peripheral regions is a matter of notable debate (Brown, 2016; Caniëls \& van den Bosch, 2011).

University research output is considered a knowledge spillover source, including through its role in creating start-ups (Acs, Braunerhjelm, Audretsch, \& Carlsson, 2009). This paper explores the context of benevolent knowledge sources (primarily a public university) and a central role of an initiative managing Intellectual Property Rights 
(IPR). The role of IP and how strength of producer rights affects spillover has been noted by Acs et al. (2009) as requiring further consideration, bringing specific relevance to this work's consideration of a novel university approach in IP commercialisation. The role of university research output, commercialised through technology transfer, as a driver of economic development has been well-established (Tornatzky \& Association, 2000). However, some research suggests only a very limited percentage of disclosures reach market and deliver income (Carlsson \& Fridh, 2002). Leyden and Link (2013) question the nature of the relationship between universities and firms, and how this translates into economic growth, including specifically the effect of R\&D subsidies. Such consideration sits alongside internal organisational factors such as examining the motivation of individual academics to engage in entrepreneurship, explored by Guerrero and Urbano (2014), with further work examining the economic contribution of knowledge spillovers and technology transfer in a UK context (Guerrero et al., 2015).

João J Ferreira, Ratten, and Dana (2017) draw upon the definition of knowledge spillovers as 'unintentional flows of knowledge from one network party to another'. This builds upon the concept developed in earlier work of David B Audretsch and Keilbach (2007) describing knowledge spillovers between parties of 'incomplete commercialisation', as a source of entrepreneurship, with other work relating this specifically to university research (Agarwal, Audretsch, \& Sarkar, 2007). Acs et al. (2009) identify start-ups using university-produced knowledge as a mechanism for knowledge spillover, including specifically where existing firms may perceive the commercial value of the knowledge as being insufficient for their interest. This is of particular importance in the Swansea Bay City Region, described in the next section, where low levels of Business Expenditure on Research \& Development (Mom et al., 2012) limit absorptive capacity (SQW, 2016). This relates directly to the ability to 
realise spillover benefits being subject to conditions within as well as outside institutions (Leyden \& Link, 2013). University spin-offs, and the importance of context to their growth is also noted by Rodríguez-Gulías, Rodeiro-Pazos, and Fernández-López (2017), including with respect to the availability of investment.

Greater understanding of the trading of knowledge between universities and firms was called for by Döring and Schnellenbach (2006), in the context of understanding regional knowledge spillovers. This brings focus to the role of Technology Transfer Offices (TTO) in supporting new venture creation, as discussed by Ghio et al. (2015), finding mixed perspectives of their benefit and noting the related issue of proximity between knowledge source and effective recipient. This consideration of spatial concentration echoes the Swansea Bay City Region (SBCR) focus on Smart Specialisation (G. H. Davies, Roderick, \& Williams, 2018; Morgan, 2013) and the aim to maximise potential for local benefit from knowledge spillover.

The scale of, and interest in, university technology transfer activity has grown significantly since the Bayh-Dole Act was passed in the United States in 1980 (Mowery, Nelson, Sampat, \& Ziedonis, 2001; Shane, 2004), with a similar increase in activity and interest amongst UK institutions occurring during the 1990s (Lambert, 2003). The potential for such activity to support economic development through new enterprise has since become of particular interest to national and regional governments including the UK (Lambert, 2003) and Wales (SBCR, 2013; WAG, 2004a; WG, 2018b). The following sections examine how technology transfer has been applied in the Swansea Bay City Region through the AgorIP initiative. This examination focuses upon its role in knowledge spillover applied to this transferable regional context exhibiting many post-industrial challenges endured elsewhere. 


\section{Swansea Bay City Region}

The regional context and dynamics, affected by institutional contexts and level of economic development, are identified as important factors for knowledge spillover (Acs, Desai, \& Hessels, 2008). This suggests the conditions of SBCR are relevant to knowledge spillover along with the activities therein which are presented later in this paper.

South west Wales is a post-industrial region which since the decline of local heavy industries in the 1980s saw a wave of Foreign Direct Investment (FDI) arrive and wane (Braczyk, Cooke, \& Heidenreich, 1998). Its economic geography can be defined by the Swansea Bay City Region (SBCR), comprising 700k residents in urban and rural communities across the City and County of Swansea, Neath Port Talbot County Borough, Carmarthenshire County, and Pembrokeshire County. Most of the region's employment and economic activity are concentrated in its urban and industrialised east around Swansea and Port Talbot which is site to the UK's largest steelworks. Low levels of BERD and entrepreneurship have stymied progress towards the region's ambitions to develop knowledge-based economic activity (SQW, 2016; WAG, 2004b). Albeit connected by motorway to the UK and Welsh capitals, SBCR can be considered a peripheral region, of the type where a university can play a significant role as a knowledge-intensive business service provider to support knowledge spillover (Pinto, Fernandez-Esquinas, \& Uyarra, 2015).

The recently announced SBCR Internet Coast City Deal aims to exploit a potential 'nexus of entrepreneurship, economic development and institutions' across public and private sectors (UKGov, 2018). This has the stated aim to foster greater levels of innovation and economic performance with strategies at both regional (SBCR, 2013; SU, 2017) and national levels (WG, 2014). The South Wales Crucible Science and Innovation Audit (SIA) (SU, 2018b) identified areas of comparative strength including 
Life Science \& Health, and Green Technologies, aligning with the Smart Specialisations (Foray, David, \& Hall, 2009) identified by the EU Commission (EU, 2017) and other notable observers (Morgan, 2013). These specialisations underpin the portfolio of projects developed within the Internet Coast programme. The City Deal aims to utilise emerging technologies including 5G connectivity as what could be considered a 'General Purpose Technology', with universities playing a role with 'co-specialised assets' (Foray et al., 2009). Combined with the aforementioned Smart Specialisation this becomes an effort to realise structural change in the sub-regional economy (Foray, 2014).

Smart Specialisation also reflects the concepts of knowledge relatedness and diversity described by Ghio et al. (2015) and is an important policy theme for Welsh Government (EU, 2017) and European Structural Funds within the region (WEFO, 2014). This approach has built upon insight from the concept of the Regional Innovation System (RIS) applied to Wales/south west Wales, noting innovation potential in high-growth sectors including Life Sciences \& Health (Abbey, Davies, \& Mainwaring, 2008; Cooke, 2004a, 2004b). This local RIS perspective includes the role of incubators and science parks to foster enterprise and innovation, examples of which have developed over recent years within SBCR (Abbey et al., 2008; G. H. Davies, S. Roderick, \& M. Williams, 2018).

The role of incubators/science parks in enhancing spillovers (Link \& Scott, 2005) was reflected in Welsh Government Policy to support greater levels of entrepreneurship, particularly in technology-based high-growth sectors (WAG, 2003, 2004a, 2004b). Investment into physical infrastructure across the region has resulted in notable debate (Abbey et al., 2008; Cooke \& Clifton, 2005; Huggins \& Kitagawa, 2012). However, a central theme throughout the debate was the need to increase the scale of activity to 
achieve stated ambitions, echoing observations of a key Welsh Government-sponsored review (Gibson S, 2007). These capacity challenges for developing the regional knowledge-economy have previously been described by a number of observers (Brooksbank \& Thomas, 2001) (Cooke, 2004b) (Huggins \& Kitagawa, 2012). In parallel, Welsh Government Policy has emphasised a role for innovation within the health system, both as a source of system improvement and to support economic development (WAG, 2010; WG, 2018a, 2018b).

\section{AgorIP}

AgorIP (Agor being Welsh language for 'Open') has been developed to provide a shared TTO for university and health system research output across south west Wales and further afield. Co-funded by European Structural Funds (ERDF), Welsh Government and Swansea University, the TTO provides a service to university and health system research output.

The initiative is based at Swansea University which is the primary research organisation within south west Wales. Industrial engagement and promotion of knowledge spillover has been in Swansea University's purpose since its founding in 1920, with its first Principal describing 'promoting regional competitive advantage through commercialising scientific research' (I. Davies, 2018). Its subsequent development over the following century then tracked that of the region, supporting industries including metals (metallurgy), life sciences \& health, ICT and renewable energy (I. Davies, 2018). Rated as a UK Top 30 institution for research excellence (HEFCE, 2014), Swansea University has grown significantly over recent years, enabled by Welsh Government policy support (WAG, 2003; WG, 2014) and EU investment (WEFO, 2007, 2014). Supporting innovation and economic development has been central to the university's growth, including the relatively recent $£ 450$ m Science \& Innovation Campus which 
opened in 2014 (I. Davies, 2018). Central to the broader expansion has been a focus on Life Sciences \& Health, with initiatives including the Institute of Life Science (ILS) and ARCH (A Regional Collaboration for Health) (ARCH, 2017), intended to develop links with the health system and industry across the region (G. Davies et al., 2018). Prior to AgorIP, these mechanisms were already embarking upon activities to support broader dissemination of knowledge, including harmonisation of IP policies and integration of R\&D/knowledge transfer functions.

AgorIP was developed in response to calls by Welsh Government and key observers to develop critical mass, along with noted regional opportunities for life sciences innovation (Abbey et al., 2008; Cooke, 2001; G. Davies et al., 2018). Developed in partnership by academia, the health service (including through $\mathrm{ARCH}$ ), Welsh Government and industry, the initiative has been created with the purpose of commercialising IP from university and clinical (primarily Health Board) research (SU, 2016). Focus upon Life Sciences \& Health aims to draw upon a sizable sector within the region, employing almost 30,000 employees in south west Wales. Alongside healthcare services, this scale also supports a significant portfolio of clinical trials/research activities involving partners ranging from global pharmaceutical firms through to indigenous medical devices companies (ARCH, 2017). AgorIP therefore creates a context different to traditional university technology transfer, instead also relating to research output from clinicians and other healthcare professionals. Therefore, AgorIP presents a more complex context, as organisation, industry and opportunity maturity are each presented as key attributes relating to spillover and entrepreneurship (Jones et al., 2018).

AgorIP operates on an individual case-by-case basis (as presented in Fig.1 below), providing support as deemed appropriate for each opportunity based upon its individual 
merits and challenges. Commercialisation may result in licensing to an existing enterprise, creation of a spin-out, or other outcome. Since the activity started in a pilot phase in April 2016 with two officers, a team of five Technology Transfer Officers has been established, aiming to develop 200+ opportunities during the period to December 2020. The initiative describes its approach as involving 'zero-waste' whereby all opportunities are progressed in some manner (SU, 2016), in an attempt to extract value from all knowledge assets though using a proportionate amount of resource in the extraction. The approach involves an aim to achieve 'investment readiness' for promising opportunities and broad dissemination of others, thereby intending to maximise quality and quantity of commercialisation. The activity works alongside partner initiatives including 'Accelerate' which aims to provide complementary support by helping address unmet clinical needs, support technology development, and assist in ecosystem engagement. In order to advance opportunities, Accelerate provides dedicated technical and clinical expertise, along with bioscientific, clinical and user experience design facilities. By working with such initiatives, AgorIP aims to maximise potential for knowledge spillover. Potential outcomes from the AgorIP Process (Fig. 1) (SU, 2016) are;

- License; providing for exclusive or non-exclusive use of the property by partner $\operatorname{organisation}(\mathrm{s})$

- Engagement; focusing on maximising potential use of the property by making it available through open source or other similar dissemination, including through sector fora

- Spin-out - Soft-start; creating a spin-out venture to support further development of the opportunity with intention of attracting commercial partner(s) 
- Spin-out - Hard-start; securing investment at the outset of the spin-out to drive commercialisation at pace and scale

Figure. 1 Here

Figure 1. AgorIP Technology Transfer Process

The 'Open Innovation' paradigm Chesbrough (2003) is applied in AgorIP with the process receiving opportunity inputs from diverse sources, at varying levels of research or development maturity, being transferred into existing and/or new markets with respect to the organisations involved. Organisations and individuals can utilise the AgorIP service on an 'Open Access' basis, potentially using other approaches as appropriate/permitted (SU, 2016). The model has already received attention from the university sector in Wales (HEFCW, 2017) and reports for UK Government (RSM, 2018), noting the level of co-investment attracted into opportunities, along with the Open Innovation approach.

\section{Approach}

This study is undertaken through a bibliographic review examining the structure of the AgorIP initiative, and how it is performing from a spatial perspective, in the context of the sectors including Life Sciences \& Health and the south west Wales RIS. This review is undertaken by examining the Project Structure, the emerging portfolio of opportunities being developed and realised, and the spatial distribution of knowledge recipients.

By examining the AgorIP project portfolio, including the nature and location of participants and knowledge recipients, the study also creates the opportunity for further research including potential and planned longitudinal and comparative studies. The study has benefited from considerable access to the initiative and its records and was supported in accessing these data by the project administrators. 
Co-financed by European Structural Funds (WEFO, 2013), the initial project phase of the AgorIP initiative maintains comprehensive records of assistance provided to academic and clinical researchers. These records include details of associated enterprises, gathered for project monitoring and evaluation purposes in order to satisfy the detailed evidence requirements of the Welsh European Funding Office on behalf of the European Commission (WEFO) (WEFO, 2009 ) including;

- Sources of opportunities, including sector, originator and location

- Originator and recipient details, including of prior involvement in technology transfer

- The form of IP involved, together with Technology Readiness Level

- Existing partners and/or identified target markets/partners

- Commercialisation Route; License/Engagement/Soft-Start/Hard-Start (as previously described)

These records provide the principle data source for this review, together with project documents including the AgorIP business plan (SU, 2016). This is taken together with the existing literature pertaining to the region's innovation system, technology transfer in general and existing consideration of AgorIP (G. H. Davies, Roderick, \& HuxtableThomas, 2018; RSM, 2018). As the portfolio is continuing to develop and outcomes emerge, it would be premature to over-analyse or interpret at this stage, though it still provides significant opportunity to identify emergent behaviours/dynamics along with future research directions. 


\section{Findings and Discussion}

This following section presents findings and discussions from the perspectives of the Project Structure, Portfolio, and Spatial distribution of knowledge recipients.

\subsection{Project Structure}

AgorIP aims to capture/protect IP prior to public disclosure, including academic conference or journal publication, which are themselves spillover mechanisms. This aims to remove a barrier to knowledge spillover by allowing for earliest possible publication of academic work without risking loss of potential IP protection. However, it could be regarded as maintaining or strengthening the barrier of IPR described by Acs et al. (2009). Furthermore, AgorIP does not exist in a vacuum, but is embedded in a complex dynamic ecosystem. It aims to accommodate this through an Open Innovation approach and working collaboratively across Wales and beyond, though this does pose a challenge in assessing its additionality without detailed appraisal of what may have happened for each opportunity in the absence of the initiative.

The Open Innovation approach aims to maximise the potential for knowledge spillover, involving mechanisms of spin-out and licensing to existing firms. In addition, an 'Engagement' outcome pathway involves less-targeted dissemination of research output for potential spillover, including through proactive promotion of traditional academic publishing via practitioner/sector fora. Use of this engagement pathway is however limited, as shown in the following section, and would need to be considered in greater detail alongside more traditional dissemination of research results and promotion of opportunities. 


\subsection{AgorIP Portfolio}

Following a pilot phase in 2016 the AgorIP project had by March 2018 been underway for 27 months. During this period it established a portfolio of 234 opportunities across sectors including Life Sciences \& Health, Information and Communications Technology, and Renewable Energy (Fig. 2). These opportunities had been drawn from academics, clinicians, industrialists and other sources (e.g. students/lone inventors) (Fig.3). Of this portfolio, 89 opportunities had achieved one of the four AgorIP outcomes. The scale and diversity of this portfolio reflects the initiative's aim to develop the region's capacity and address noted deal flow challenges (Gibson S, 2007), with focus upon identified smart specialisations (Morgan, 2013) subsequently captured in the SIA (SU, 2018a). Furthermore, 19 of these spin-outs involved both IP and investment, indicators noted as indicating potentially higher survivability than spin-outs without these attributes (Rodeiro-Pazos, Rodríguez-Gulías, \& Fernández-López, 2017).

Figure. 2 Here

Figure 2. AgorIP Opportunities by Sector

Figure. 3 Here

Figure 3. AgorIP Opportunities by Originator

The predominant sector within the AgorIP portfolio (Fig. 2) is Life Sciences \& Health. This reflects the engagement with $\mathrm{ARCH}$, other entities within NHS Wales and organisations such as the Institute of Life Sciences within Swansea University Medical School. It also aligns with the activity surrounding 'mini-agglomerations' previously originally noted by academic study (Cooke, 2001) and government policy development (DTI, 2001; SU, 2018a). This bias towards life sciences opportunities reflects the 
observation by Carlsson and Fridh (2002) of TTOs being kept busiest in universities with a medical school. The strong showing of ICT within the portfolio also reflects strengths noted in the SIA (SU, 2018a), and targeted by the SBCR Internet Coast City Deal (SU, 2017).

Of the opportunities which had achieved an outcome, 48 (more than half) had resulted in new ventures and 39 had been licensed to established firms. The breakdown by sector presented in fig. 4 shows varying predominance of route by sector. Life Sciences $\&$ Health and Engineering involved notably more licensing outcomes than other sectors, which may relate to higher levels of existing industrial collaboration.

Figure. 4 Here

Figure 4. AgorIP Commercialisation Pathways by Sector Opportunities which had attained outcomes also presented 27 of 52 (i.e. 52\%) with entrepreneurial academics having had prior experience of spin-out/licensing activity, reflecting consideration of the role of experience in academic's entrepreneurial intentions (Guerrero \& Urbano, 2014). It must be noted though that the vast majority of AgorIP opportunities are still to mature and this balance may change.

\subsection{Spatial Distribution}

Across the 234 opportunities within the AgorIP portfolio, 141 external engagements were recorded with organisations developing opportunities based upon SBCR research output. The presence of an Institute of Life Science (ILS) on-campus business incubator explains a local grouping of 20 associated firms (Fig. 5 below). These opportunities all related to spin-out companies involving academics and/or clinicians from the neighbouring Singleton Hospital. 
The ILS-centred grouping echoes findings that Science Parks/Incubators enhance knowledge spillover (Link \& Scott, 2005). Within the SBCR region the spatial distribution also featured foci upon other business incubator facilities, predominantly in or around Swansea city. These concentrations also align with the suggestion from David B. Audretsch and Lehmann (2005) of the role that infrastructure plays in knowledge spillover by supporting absorption of knowledge into young firms.

Figure. 5 Here

Figure 5. AgorIP Commercial Partners by location - Institute of Life Science and Swansea Bay City Region

In a broader spatial context (Fig.6), the concentration within the SBCR locality and M4 corridor reflects the 100km effective radius noted by Hewitt-Dundas (2012), describing the importance of proximity for collaboration with both codified and tacit knowledge. Albeit somewhat fewer, a similar pattern can be seen along the A55 main route through North Wales. While not so proximate, these engagements still exist in the Welsh ecosystem of support, initiatives and sector fora.

The broader distribution (Fig.6) shows relatively limited though still apparent engagement further east. This may relate to an encouraging level of local absorptive capacity (Qian \& Acs, 2013) from effective smart specialisations across the region (SQW, 2016), resulting in fewer opportunities being realised outside the region. However, eligibility constraints of the ERDF support (WEFO, 2013) requires activity to be focused within West Wales providing a bias towards SBCR where efforts of the team are concentrated. However, engagements further afield do imply the claimed Open Innovation approach (SU, 2016) is resulting in wider engagement and impact. 
Figure 6. AgorIP Commercial Partners by location - UK

\section{Conclusion and Implications}

This paper has explored the novel technology transfer initiative of AgorIP, examining how knowledge spillover relates to the peripheral south Wales post-industrial region. In terms of context it has also introduced a new entrepreneurial ecosystem involving academic/health system collaboration, thereby aiming to help increase the depth and breadth of perspectives called for by Jones et al. (2018). In this respect, the AgorIP portfolio reflects the strengths noted amongst regional Smart Specialisations (EU, 2017) showing how exercises such as the recent Science and Innovation Audit (SU, 2018b) can identify potential areas for focus to support spillover and reduce knowledge filter. Focusing upon this context, the majority of AgorIP opportunities were found to be within Life Sciences \& Health, suggesting the sector can be targeted though due to the early stage of activity the initiative's impact remains to be seen.

\subsection{Implications and Future Research}

AgorIP is an example of response to the requirement identified by João JM Ferreira and Carayannis (2019) to identify national strategic responses for disseminating knowledge to industry. The initiative has shown knowledge spillover occurring in the complex context of academic and health system knowledge across the local RIS. Deeper analysis of the portfolio could potentially provide opportunity for insight as to how spillover occurs in different sectors while subject to similar institutional conditions.

This work has demonstrated how spillover activity can be scaled across organisations and sectors, which offers research opportunity within and across multiple contexts. The initiative also offers scope, as the portfolio evolves, to respond to the call from João JM 
Ferreira and Carayannis (2019) for longitudinal study to develop understanding impact and evolution of University-Industry interaction.

Spatial distribution of activity shows how consideration of AgorIP must look beyond west Wales to understand its impact, even with the geographical focus of ERDF support. This has clear implications for both academic research and project evaluation. In parallel, the range of commercialisation pathways and the decisions made to one over another, including the 'zero-waste' philosophy also provide potential scope for further research.

\subsection{Managerial Implications}

As noted by Guerrero et al. (2015), there is a challenge for university management and TTO to align resource. However, the AgorIP initiative extends this challenge to a more complex context which also includes the health system and the multiple organisations and stakeholders this entails.

In terms of initial productivity, the number of spin-outs produced by AgorIP both locally and further afield suggests knowledge spillover is occurring, though the survival and development of these ventures clearly remains to be seen. In this respect, growing spin-outs and attracting investment are important factors (Ghio et al., 2015) to maximise impact and sustain the initiative.

Originators of AgorIP opportunities are predominantly academics, suggesting more work may remain to be done to engage clinicians, not least considering the scale of the health system in Wales. Furthermore, the importance of working with other initiatives such as Accelerate to support ongoing development is a further important consideration for practice, which is a challenge noted in other regions (Daniel \& Alves, 2019). 


\subsection{Policy Implications}

The increased scale of activity shows a positive response to the issue of a lack of scale noted by Gibson S (2007) and therefore should make interventions such as AgorIP of interest to policymakers. Spatially, the grouping of opportunities being exploited along the M4 shows a concentration within the Welsh-Government-desired region.

The activity does though still reside in the challenging regional context of SBCR which lacks the 'critical mass' of local technology-employment considered as important to realise and benefit from spillovers (Varga, 2000). As such, care may be required to avoid the 'lock-in' of focus around university research described by Brown (2016). This could entail continued consideration of the broader innovation ecosystem, beyond academia, including the health system and private sector as critical actors. While not over-emphasising the role of academia in driving policy direction, alignment of organisational strategies, as described by Hewitt-Dundas (2012) requires consideration, particularly to focus benefit from high research intensity institutions within the region. However, the challenge for policy-makers is multi-faceted and does not start or stop with interventions such as AgorIP. The evolution of its context through initiatives such as the SBCR City Deal and policies ranging from health to economic development need all to be aligned in order to maximise their benefits.

\section{Acknowledgements}

The authors would like to thank Prof. Ifan Evans of Welsh Government, Dr. Mark Bowman of Arche Innovations for their support in undertaking this work, and Ms Kasia Williams of AgorIP for kindly providing data from the meticulous project records.

\section{References}


Abbey, J., Davies, G., \& Mainwaring, L. (2008). Vorsprung durch Technium: Towards a system of Innovation in South-west Wales. Regional Studies, 42(2), 281-293.

Acs, Z. J., Braunerhjelm, P., Audretsch, D. B., \& Carlsson, B. (2009). The knowledge spillover theory of entrepreneurship. Small business economics, 32(1), 15-30.

Acs, Z. J., Desai, S., \& Hessels, J. (2008). Entrepreneurship, economic development and institutions. Small business economics, 31(3), 219-234.

Agarwal, R., Audretsch, D., \& Sarkar, M. (2007). The process of creative construction: knowledge spillovers, entrepreneurship, and economic growth. Strategic Entrepreneurship Journal, 1(3-4), 263-286.

ARCH. (2017). A Regional Collaboration for Health

Audretsch, D. B., \& Keilbach, M. (2007). The theory of knowledge spillover entrepreneurship. Journal of Management Studies, 44(7), 1242-1254.

Audretsch, D. B., \& Lehmann, E. E. (2005). Does the Knowledge Spillover Theory of Entrepreneurship hold for regions? Research Policy, 34(8), 1191-1202. doi:http://dx.doi.org/10.1016/j.respol.2005.03.012

Braczyk, H.-J., Cooke, P. N., \& Heidenreich, M. (1998). Regional innovation systems: the role of governances in a globalized world: Psychology Press.

Brooksbank, D., \& Thomas, B. (2001). An assessment of higher education spin-off enterprises in Wales. Industry and Higher Education, 15(6), 415-420.

Brown, R. (2016). Mission impossible? Entrepreneurial universities and peripheral regional innovation systems. Industry and Innovation, 23(2), 189-205. doi:10.1080/13662716.2016.1145575

Caniëls, M. C., \& van den Bosch, H. (2011). The role of higher education institutions in building regional innovation systems. Papers in Regional Science, 90(2), 271286.

Carlsson, B., \& Fridh, A.-C. (2002). Technology transfer in United States universities. Journal of Evolutionary Economics, 12(1-2), 199-232.

Charles, D. (2003). Universities and territorial development: reshaping the regional role of UK universities. Local Economy, 18(1), 7-20.

Chesbrough, H. (2003). Open innovation: Boston: Harvard Business School Press.

Cooke, P. (2001). Biotechnology Clusters in the U.K.: Lessons from Localisation in the Commercialisation of Science. Small business economics, 17(1-2), 43-59. doi:10.1023/A:1011193531172

Cooke, P. (2004a). Life sciences clusters and regional science policy. Urban Studies, 41(5-6), 1113-1131.

Cooke, P. (2004b). The regional innovation system in Wales. London: Routledge.

Cooke, P., \& Clifton, N. (2005). Visionary, precautionary and constrained 'varieties of devolution'in the economic governance of the devolved UK territories. Regional Studies, 39(4), 437-451.

Daniel, A. D., \& Alves, L. (2019). University-industry technology transfer: the commercialization of university's patents. Knowledge Management Research \& Practice, 1-21.

Davies et al., G. (2018). Life Sciences \& Health in south west Wales: A Sub-regional Innovation System In J. James, J. Preece, \& R. Valdes-Cotera (Eds.), Entrepreneurial Learning City Regions (pp. p267-295): Springer.

Davies, G. H., Roderick, S., \& Huxtable-Thomas, L. (2018). Social commerce Open Innovation in healthcare management: an exploration from a novel technology transfer approach. Journal of Strategic Marketing, 1-12. 
Davies, G. H., Roderick, S., \& Williams, M. (2018). A sub-regional innovation ecosystem? Life sciences and health in the Swansea Bay City Region. International Journal of Innovation and Regional Development, 8(4), 15. doi:10.1504/IJIRD.2018.097456

Davies, I. (2018). The Impact of a Research-led Entrepreneurial University on a Regional Economy: Swansea University's Science and Innovation Campus Entrepreneurial Learning City Regions (pp. 191-210): Springer.

Döring, T., \& Schnellenbach, J. (2006). What do we know about geographical knowledge spillovers and regional growth?: A survey of the literature. Regional Studies, 40(03), 375-395.

DTI. (2001). Business Clusters in the UK - a first assessment. Department of Trade and Industry, Crown Copyright

Etzkowitz, H., \& Leydesdorff, L. (2000). The dynamics of innovation: from National Systems and "Mode 2" to a Triple Helix of university-industry-government relations. Research Policy, 29(2), 109-123. doi:http://dx.doi.org/10.1016/S00487333(99)00055-4

Etzkowitz, H., Webster, A., Gebhardt, C., \& Terra, B. R. C. (2000). The future of the university and the university of the future: evolution of ivory tower to entrepreneurial paradigm. Research Policy, 29(2), 313-330.

EU. (2017). Wales Smart Specialisations. Retrieved from http://s3platform.jrc.ec.europa.eu/regions/UKL/tags/UKL

Faria, J., Mixon, F., \& Upadhyaya, K. (2019). Public policy and the university-industry R\&D nexus. Knowledge Management Research \& Practice, 17(4), 499-506.

Ferreira, J., Fayolle, A., Ratten, V., \& Raposo, M. (2018). Entrepreneurial Universities: Collaboration, Education, and Policies: Edward Elgar. Cheltenham

Ferreira, J. J., \& Carayannis, E. G. (2019). University-industry knowledge transferunpacking the "black box": an introduction: Taylor \& Francis.

Ferreira, J. J., Ratten, V., \& Dana, L.-P. (2017). Knowledge spillover-based strategic entrepreneurship. International Entrepreneurship and Management Journal, 13(1), 161-167.

Foray, D. (2014). Smart specialisation: opportunities and challenges for regional innovation policy (Vol. 79): Routledge. Abingdon-on-Thames

Foray, D., David, P. A., \& Hall, B. (2009). Smart specialisation-the concept. Knowledge economists policy brief, 9(85), 100.

Ghio, N., Guerini, M., Lehmann, E. E., \& Rossi-Lamastra, C. (2015). The emergence of the knowledge spillover theory of entrepreneurship. Small business economics, 44(1), 1-18.

Gibb, A., \& Hannon, P. (2006). Towards the entrepreneurial university. International Journal of Entrepreneurship Education, 4(1), 73-110.

Gibson S. (2007). Commercialisation in Wales - A Report by the Independent Task and Finish Group. Retrieved from www.assembly.wales/commercialisation_in_wales_-_gibson_review.pdf

Guerrero, M., Cunningham, J. A., \& Urbano, D. (2015). Economic impact of entrepreneurial universities' activities: An exploratory study of the United Kingdom. Research Policy, 44(3), 748-764.

Guerrero, M., \& Urbano, D. (2014). Academics' start-up intentions and knowledge filters: An individual perspective of the knowledge spillover theory of entrepreneurship. Small business economics, 43(1), 57-74. 
HEFCE. (2014). Research Excellence Framework 2014: The results. Retrieved from https://www.ref.ac.uk/2014/media/ref/content/pub/REF\%2001\%202014\%20$\% 20$ full\%20document.pdf.

HEFCW. (2017). Innovation Nation. Higher Education Funding Council for England, Retrieved from https://www.hefcw.ac.uk/publications/hefcw_reports_and_statistics/innovation nation.aspx.

Hewitt-Dundas, N. (2012). Research intensity and knowledge transfer activity in UK universities. Research Policy, 41(2), 262-275. doi:http://dx.doi.org/10.1016/j.respol.2011.10.010

Huggins, R., \& Kitagawa, F. (2012). Regional Policy and University Knowledge Transfer: Perspectives from Devolved Regions in the UK. Regional Studies, 46(6), 817-832. doi:10.1080/00343404.2011.583913

Jones, P., Klapper, R., Ratten, V., \& Fayolle, A. (2018). Emerging themes in entrepreneurial behaviours, identities and contexts. The International Journal of Entrepreneurship and Innovation, 19(4), 233-236.

Lambert, R. (2003). Lambert Review of Business-University Collaboration: Final Report. HMSO.

Leyden, D. P., \& Link, A. N. (2013). Knowledge spillovers, collective entrepreneurship, and economic growth: the role of universities. Small business economics, 41(4), 797-817.

Leydesdorff, L., \& Etzkowitz, H. (1998). The triple helix as a model for innovation studies. Science and public policy, 25(3), 195-203.

Link, A. N., \& Scott, J. T. (2005). Opening the ivory tower's door: An analysis of the determinants of the formation of US university spin-off companies. Research Policy, 34(7), 1106-1112.

Mom, T. J. M., Oshri, I., \& Volberda, H. W. (2012). The skills base of technology transfer professionals. Technology Analysis \& Strategic Management, 24(9), 871-891. doi:10.1080/09537325.2012.718663

Morgan, K. (2013). The regional state in the era of Smart Specialisation. Ekonomiaz, 83(02), 103-126.

Mowery, D. C., Nelson, R. R., Sampat, B. N., \& Ziedonis, A. A. (2001). The growth of patenting and licensing by U.S. universities: an assessment of the effects of the Bayh-Dole act of 1980. Research Policy, 30(1), 99-119. doi:http://doi.org/10.1016/S0048-7333(99)00100-6

Pinto, H., Fernandez-Esquinas, M., \& Uyarra, E. (2015). Universities and knowledgeintensive business services (KIBS) as sources of knowledge for innovative firms in peripheral regions. Regional Studies, 49(11), 1873-1891.

Qian, H., \& Acs, Z. J. (2013). An absorptive capacity theory of knowledge spillover entrepreneurship. Small business economics, 40(2), 185-197. doi:10.1007/s11187-011-9368-x

Ratten, V. (2017). Entrepreneurial universities: the role of communities, people and places. Journal of Enterprising Communities: People and Places in the Global Economy, 11(03), 310-315.

Rodeiro-Pazos, D., Rodríguez-Gulías, M. J., \& Fernández-López, S. (2017). The effectiveness of entrepreneurial universities at creating surviving firms. Journal of Enterprising Communities: People and Places in the Global Economy.

Rodríguez-Gulías, M. J., Rodeiro-Pazos, D., \& Fernández-López, S. (2017). The effect of university and regional knowledge spillovers on firms' performance: an 
analysis of the Spanish USOs. International Entrepreneurship and Management Journal, 13(1), 191-209.

RSM. (2018). A Report for the Department of Business, Energy, and Industrial Strategy (BEIS), Research into issues around the commercialisation of university IP. Retrieved from Online:

https://assets.publishing.service.gov.uk/government/uploads/system/uploads/atta chment_data/file/699441/university-ip-commercialisation-research.pdf

SBCR. (2013). Swansea Bay City Region Economic Regneration Strategy. Online.

Shane, S. (2004). Encouraging university entrepreneurship? The effect of the Bayh-

Dole Act on university patenting in the United States. Journal of Business Venturing, 19(1), 127-151.

SQW. (2016). Swansea Bay City Region: Update to the Swansea Bay City Region Economic Strategy Economic Context Chapter. Retrieved from Online:

SU. (2016). AgorIP Business Plan. Retrieved from

SU. (2017). Internet Coast: Phase 1: City Deal Proposal Impact Appraisal. Retrieved from School of Management:

SU. (2018a). South Wales Crucible: Final Report. Retrieved from https://www.southwalescrucible.co.uk/

SU. (2018b). South Wales Crucible: Initial Report. Retrieved from

Teixeira, S. J., Veiga, P. M., \& Fernandes, C. A. (2019). The knowledge transfer and cooperation between universities and enterprises. Knowledge Management Research \& Practice, 17(4), 449-460.

Tornatzky, L. G., \& Association, N. G. (2000). Building state economies by promoting university-industry technology transfer: National Governors' Association.

UKGov. (2018). Swansea Bay City Region City Deal. Online Retrieved from https://assets.publishing.service.gov.uk/government/uploads/system/uploads/atta chment_data/file/611685/Swansea_City_Deal__English.pdf.

Varga, A. (2000). Local academic knowledge transfers and the concentration of economic activity. Journal of Regional Science, 40(2), 289-309.

WAG. (2003). Wales for Innovation. Welsh Assembly Government. Crown Copyright.

WAG. (2004a). Knowledge Economy Nexus: Role of Higher Education in Wales. Welsh Assembly Government, Crown Copyright

WAG. (2004b). People, Places, Futures: The Wales Spatial Plan. Welsh Assembly Government. Crown Copyright.

WAG. (2010). Economic Renewal: a new direction. Welsh Assembly Government, Crown Copyright.

WEFO. (2007). Approved Projects, 2000-2006 West Wales \& Valleys Operational Programme. In W. G. Welsh European Funding Office (Ed.). Online.

WEFO. (2009). ERDF Indicators, Definitions and Evidence Requirements. Web Retrieved from https://gweddill.gov.wales/funding/eu-funds/2014-2020/wefoguidance/index9ed2.html?lang=en.

WEFO. (2013). European Structural Funds programmes 2014-2020, West Wales and the Valleys European Regional Development Fund Operational Programme. Retrieved from https://gov.wales/docs/wefo/publications/evaluation/171205-expost-evaluation-2007-2013-final-report-en.pdf.

WEFO. (2014). The Economic Prioritisation Framework for Welsh European Funds:

Version 2. Welsh European Funding Office, Crown Copyright

WG. (2014). Innovation Wales, Welsh Government, Crown Copyright. 
WG. (2018a). Healthier Wales. Online: Welsh Government, Crown Copyright

Retrieved from https://gov.wales/sites/default/files/publications/2019-04/in-

brief-a-healthier-wales-our-plan-for-health-and-social-care.pdf.

WG. (2018b). Review of Government Funded Research and Innovation in Wales.

Online Retrieved from https://gweddill.gov.wales/docs/det/publications/reidreview-en.pdf. 